\title{
DELIMITAÇÃO E PROTEÇÃO JURÍDICA DO KNOW-HOW NOS CONTRATOS DE FRANQUIA A PARTIR DA VISÃO BASEADA EM CONHECIMENTO
}

\author{
Fernanda Carvalho Frustockl La Rosa ${ }^{1}$ \\ Silvio Bitencourt da Silva ${ }^{2}$
}

Resumo: O know-how não é passível de registro e tem difícil delimitação, porém é o recurso estratégico principal para a competitividade em franquias. A partir disso, este trabalho avalia as possibilidades de proteção conferidas pelo ordenamento jurídico brasileiro em relação ao conhecimento, em especial o know-how, gerado no âmbito das relações de franquia, desde a contratação da franquia e durante todo o curso da relação. Adota-se a base teórica da Visão Baseada em Conhecimento em um estudo de caso com empresas franqueadoras brasileiras. Os principais achados da pesquisa se relacionam com a proposição de ferramentas que visam à proteção do know-how.

Palavras-chave: Conhecimento; Contratos; Franquias; Know-how; Recurso.

\section{DELIMITATION AND LEGAL PROTECTION OF KNOW-HOW IN FRANCHISE CONTRACTS FROM KNOWLEDGE-BASED VISION}

Abstract: The know-how is not subject to registration and is difficult to define, but it is the main strategic resource for competitiveness in franchises. Based on this, this work assesses the possibilities of protection afforded by the Brazilian legal system in relation to knowledge, especially the know-how, generated within the scope of franchise relationships, since the franchise contracting and throughout the course of the relationship. The theoretical basis of the Knowledge Based View is adopted in a case study with Brazilian franchising companies. The main findings of the research are related to the proposition of tools aimed at protecting know-how.

Keywords: Contracts; Franchises; Know-how; Knowledge; Resource.

\section{INTRODUÇÃO}

O know-how pode ser definido como um tipo de conhecimento singular construído a partir da experiência de uma empresa franqueadora. O know-how não é passível de registro e

\footnotetext{
Mestra em Direito da Empresa e dos Negócios pela UNISINOS (2020). Especialista em Direito Empresarial com Ênfase na Advocacia Empresarial pela PUCRS (2015). Graduada em Direito pela Pontifícia Universidade Católica do Rio Grande do Sul PUCRS (2012), tendo cursado um semestre da graduação na modalidade de Mobilidade Acadêmica na Eberhard Karls Universität Tübingen (2011). Advogada. Identificadores (ID): ORCID: http://orcid.org/0000-0002-0238-0866Lattes: http://lattes.cnpq.br/1226441180936858 E-mail: fernanda.larosa@baptistaluz.com.br

${ }^{2}$ Doutorado em Administração de Empresas pela Universidade do Vale do Rio do Sinos - UNISINOS. Atualmente exerce a função de professor na Escola de Direito (Mestrado Profissional em Direito da Empresa e dos Negócios) e na Escola de Gestão e Negócios (MBAs em Gestão e Graduação em Inovação e Liderança) nos campos da inovação e estratégia; e a função de Gerente de Pesquisa, Desenvolvimento e Inovação na Unidade Acadêmica de Pesquisa e Pós-Graduação da Universidade do Vale do Rio do Sinos UNISINOS. Identificadores (ID): ORCID: http://orcid.org/0000-0002-3976-1582 Lattes: http://lattes.cnpq.br/5792727067633222

E-mail: sibitencourt@unisinos.br
} 
tem difícil delimitação, porém é o recurso estratégico principal para a competitividade em franquias. Além disso, o know-how pode ser considerado como um conhecimento em constante evolução. Em que pese o processo de transferência de know-how seja bem definido no início da relação de franquia, através da entrega de manuais e realização de treinamentos, ele não se esgota nesta etapa, sendo possível afirmar que há criação - ou até mesmo, cocriação - e transferência de know-how durante toda a extensão da relação de franquia.

Os sistemas de franquia são regulados no Brasil pela Lei 13.966/2019 (Nova Lei de Franquias), que revogou a Lei 8.955/95. Assegura ao franqueado o acesso às informações indispensáveis para a ponderação das vantagens e desvantagens relacionadas à adesão a determinado sistema de franquias, mas ainda não se dedica a regular os direitos e obrigações das partes envolvidas no contrato de franquia.

Diante disso, o presente trabalho busca ampliar o entendimento sobre o conceito de conhecimento nas relações de franquia, com foco específico no know-how, tendo como objetivo compreender as formas de proteção jurídica do know-how gerado no âmbito dessas relações.

A discussão acerca da delimitação e da proteção jurídica do know-how nas relações de franquia demonstra ser um campo de estudo relevante, especialmente se associado a discussões que se apoiem na base teórica reconhecida como Visão Baseada em Recursos VBR e uma de suas expansões que se refere à Visão Baseada em Conhecimento - VBC, indicando a gestão de conhecimento em franchising como uma agenda de pesquisa para o futuro. (WELSH et al, 2011; PERRIGOT e PÉNARD, 2013; HUSSLER e RONDE, 2017; GOROVAIA, 2017; FU-SHENG et al., 2017; GOROVAIA e WINDSPERGER, 2018; IDDY e ALON, 2019) e que fornecem fundamentos sólidos para responder à questão de pesquisa que norteia este trabalho: como é protejido juridicamente o know-how gerado nas relações entre franqueadores e franqueados? Assim, esse trabalho tem como objetivo geral avaliar as possibilidades de proteção conferidas pelo ordenamento jurídico brasileiro em relação ao conhecimento, especialmente o know-how, gerado no âmbito das relações de franquia, entre franqueadores e franqueados, desde a contratação da franquia e, também, durante todo o curso da relação. Para alcançar o objetivo proposto, foi conduzido um estudo de caso junto a três empresas franqueadoras com atuação majoritária no Brasil. Espera-se, ainda, contribuir com resposta a Dant et al (2011), que identificaram a carência de estudos com base experimental nas pesquisas sobre franchising. 


\section{REFERENCIAL TEÓRICO}

O franchising é objeto de estudo de variadas áreas, já tendo sido pesquisado sob as perspectivas de variadas ciências como o Empreendedorismo, o Marketing, a Economia, a Gestão Estratégica, o Direito, entre outros (COMBS et al, 2004, p. 908). Particularmente, em relação ao conhecimento, grande parte dos estudos analisa os contratos sob a ótica da teoria da agência e dos custos de transação, deixando de observar a relação de franquia sob a perspectiva da transmissão de conhecimento e competências (HUSSLER e RONDE, 2017, p. 429).

Em pesquisa conduzida com o objetivo de identificar o desenvolvimento teórico dos estudos sobre franquias, COMBS et al (2004) identificaram que as bases teóricas mais utilizadas são a Teoria da Agência e a Escassez de Recursos. Em outra pesquisa conduzida com o mesmo objetivo, DANT et al (2011) concluíram que os estudos sobre franquias foram realizados, majoritariamente, pelas lentes da Teoria da Agência, dos Custos de Transação e de teorias de Escassez de Recursos ou Aquisição de Recursos, ambas com suas raízes na Teoria da Visão Baseada em Recursos (VBR). Por isso, dada a natureza estratégica e relevante dos recursos intangíveis em franchising e considerando, ainda, o objetivo do presente trabalho, entendeu-se que a base teórica mais adequada para o estudo é a VBR e, mais especificamente o seu desdobramento teórico Visão Baseada no Conhecimento (VBC), sobre o qual se expõe a seguir.

\subsection{Da Teoria da Visão Baseada em Conhecimento}

A VBC é uma expansão teórica da VBR que tem sua origem com Robert Grant (1996) em que o conhecimento é percebido como o recurso mais importante de uma empresa (GRANT, 1996, p. 110). Segundo essa teoria, o conhecimento é o insumo estratégico para produção e fonte primária de valor para uma empresa (GRANT, 1996, p. 112). O conhecimento pode ser subjetivo ou objetivo, tácito ou explícito, procedimental ou declaratório, pessoal ou organizacional (GRANT, 1996). Esse trabalho foca somente na distinção entre conhecimento tácito e explícito, porque essas características do conhecimento implicam em maior ou menor dificuldade na tangibilização do conhecimento e na definição de mecanismos adequados para sua transferência, conforme o tipo de conhecimento em questão, o que é relevante para franqueadores e franqueados. 
O conhecimento explícito é revelado através da sua comunicação, o conhecimento tácito é revelado através da sua aplicação e adquirido pela prática (GRANT, 1996, p. 111). O conhecimento tácito é do tipo mais difícil de codificar e transferir, pois se trata de conhecimento não verbalizado e intuitivo, que possui um caráter pessoal, que o torna mais complexo de comunicar e formalizar (BATTISTELLA et al, 2016). Há desafios relacionados ao uso e transferência de ambos, pois mesmo que o conhecimento esteja estruturado e codificado (explícito), é necessário, ainda, torná-lo acessível às pessoas que devem utilizá-lo, bem como garantir que elas absorvam esse conhecimento (BATTISTELLA et al, 2016).

O conhecimento, como principal recurso de uma empresa, apresenta desafios também quanto à sua apropriabilidade. O conhecimento tácito não pode ser diretamente apropriado porque não pode ser diretamente transferido; o conhecimento explícito, por sua, vez pode ser apropriado somente através da sua aplicação em atividade produtiva (GRANT, 1996, p. 111).

Considerando a crescente relevância do conhecimento como recurso organizacional principal, Nonaka et al (2013) propõem um novo modelo organizacional batizado de “organização dinâmica fractal”, fundamentado na ideia da tríade do conhecimento, que consiste na integração e síntese do conhecimento tácito e explícito para fins de criar um terceiro tipo de conhecimento, denominado "phronesis". Esta tríade consiste em um processo espiral de conversão de conhecimento tácito e explícito e propicia a transformação e disseminação do conhecimento através da empresa e entre empresas.

Nesse aspecto, também é relevante apresentar o conceito de capacidade absortiva proposto por Cohen e Levinthal (1990, p. 128), caracterizado como a habilidade de uma empresa em avaliar, utilizar e explorar conhecimento obtido externamente. Em franchising, a capacidade absortiva é importante para medir a capacidade do franqueado em criar, armazenar, transformar, receber, replicar e aplicar o conhecimento (IDDY e ALON, 2019).

A perspectiva teórica da VBC permite analisar as relações que se desenvolvem entre franqueadores e franqueados por meio do contrato de franquia, especialmente no que diz respeito à transferência de conhecimento e, mais especificamente, de know-how.

\subsection{Do Conhecimento (Know-how) nas Relações de Franquias}

O franchising foi regulamentado no Brasil por meio da Lei n. 8.955 de 1994, apesar de já ser adotado como modelo de negócios muito antes disso. Recentemente, a referida lei foi 
revogada pela Lei n. 13.966/2019 (Nova Lei de Franquias), que introduziu algumas novidades no texto legislativo mas não modificou a estrutura e a lógica da lei anterior.

$\mathrm{Na}$ doutrina jurídica, o contrato de franquia ficou classificado como um contrato do gênero de colaboração, através do qual firma-se uma parceria entre duas empresas (ROQUE, 2012, p. 21) caracterizada como a "operação pela qual um empresário concede a outro o direito de usar a marca de produto seu com assistência técnica para a sua comercialização, recebendo, em troca, determinada remuneração" (GOMES, 2008, p. 578). Trata-se de "contrato que liga uma pessoa a uma empresa, para que esta, mediante condições especiais, conceda à primeira o direito de comercializar marcas ou produtos de sua propriedade sem que, contudo, a esses estejam ligadas por vínculo de subordinação” (MARTINS, 1998, p. 486). O franchising pode ser explicado, ainda, como um método para a distribuição de produtos e/ou serviços, por meio da parceria firmada entre uma empresa, geralmente mais experiente, e outras, geralmente menos experientes, no qual a primeira transfere às últimas a experiência ou competência (ou seja, o know-how) por ela desenvolvido (ROQUE, 2012, p. 15).

Os sistemas de franquia podem se manifestar, na prática, de diferentes formas. Em alguns modelos, a tecnologia de implantação e administração não faz parte do negócio. Disso depreende-se a existência de duas modalidades de franchising, quais sejam: a modalidade tradicional e a de negócio formatado ou de modelo de negócio (Business Format Franchising). A diferença entre essas duas modalidades está na forma de gestão. $\mathrm{Na}$ modalidade tradicional de franquia, a relação entre franqueador e franqueado envolve apenas o direito de distribuir ou comercializar os produtos da marca do franqueador com exclusividade, podendo-se citar, como exemplos, as relações estabelecidas entre as montadoras de veículos e as revendedoras autorizadas, ou entre as distribuidoras de petróleo com os postos de gasolina, os quais operam com a "bandeira" do distribuidor (LEITE, 1991, p. 31 a 33). Na modalidade de Business Format Franchising, por outro lado, há uma transferência, pelo franqueador ao franqueado, de técnicas industriais e/ou métodos de administração e comercialização anteriormente desenvolvidas por ele, licenciando ao franqueado a marca e o conjunto de direitos de propriedade incorpóreos, para que este opere sob sua supervisão e assessoria técnica na fabricação e/ou vendas de seus produtos e/ou serviços, mediante uma compensação financeira firmada em contrato (LEITE, 1991, p. 37 a 42; COULON e CANTALI, 2019, p. 107). 
O foco deste trabalho está direcionado às franquias da modalidade Business Format Franchising, nas quais é possível afirmar que um dos principais elementos do contrato de franquia é a transferência de conhecimento do franqueador para o franqueado, pois um dos objetivos mais relevantes do franchising é "facilitar a repetição da operação criada e desenvolvida pela marca franqueadora por seus franqueados" (GUETTA ET AL, 2013, p. 162). Assim, o modelo de negócio do franchising repousa na criação de conhecimentos específicos pelo franqueador, e na sua replicação pelos franqueados.

\subsubsection{Das Definições de Conhecimento e Know-How nas Relações de Franquia}

Nas relações de franquia, o conhecimento pode ser definido como o fluxo de mensagens organizado, inicialmente criado no âmbito da empresa franqueadora, relativo ao modo de implantar, operar e promover uma unidade de negócio vinculada àquela respectiva empresa. A transmissão desse conhecimento desenvolvido pela franqueadora aos franqueados é um dos elementos da relação de franquia previsto, inclusive, na definição de sistema de franquia estabelecida pela Lei de Franquias.

Ao tratar do contrato de franquia, em clássico artigo sobre o tema, Comparato (1975, p. 53-54) o diferencia do contrato de concessão de venda ao defender que, na franquia, além da distribuição de produtos e da licença de uso da marca, o elemento essencial está na prestação de serviços de organização e métodos de venda pelo franqueador ao franqueado. Não obstante, é possível destacar que os três pilares da operação de franquias são os manuais, o treinamento e a consultoria de campo, justamente as ferramentas utilizadas pela franqueadora para repassar conhecimento (GUETTA ET AL., 2013, p. 161).

Conforme definido na seção anterior, o conhecimento a ser transferido no âmbito das relações de franquia pode ser de natureza explícita ou tácita. O conhecimento explícito pode ser escrito, codificado e facilmente transferido; o conhecimento tácito é pessoal, baseado em experiência e, por sua vez, difícil de ser transferido.

Em franchising, o conhecimento explícito é formalizado através dos contratos, dos manuais de franquia, circulares, normativas ou quaisquer outras fontes escritas fornecidas aos franqueados; o conhecimento tácito, por outro lado, somente pode ser transferido em contatos pessoais com os franqueados, durante treinamentos, workshops, reuniões, consultorias e supervisão de campo (GOROVAIA, 2017, p. 236). 
O conhecimento tácito, em franchising, é de extrema importância para permitir o desenvolvimento e a interpretação do conhecimento explícito. Muito do conhecimento tácito dos franqueadores e suas capacidades organizacionais estão armazenados junto a pessoas chave da organização, na matriz da franqueadora, e nas lojas. A interação entre os membros da franqueadora e os franqueados permitirá um entendimento e aplicação do conhecimento muito mais efetivos do que a mera imposição de leitura de manuais e outras fontes escritas aos franqueados (GOROVAIA, 2017, p. 236).

Quando se trata de conhecimento em franquias, o conceito de know-how possui relevância, uma vez que o know-how é o conjunto de conhecimentos singulares construídos a partir da experiência de uma empresa franqueadora, os quais são processuais e ligados ao saber-fazer alguma coisa (KOGUT, 1992), constituindo o recurso estratégico principal para a competitividade em franquias. Conforme será tratado a seguir, o know-how é formado por um conjunto de conhecimentos específicos, mas nem todo conhecimento integra o know-how.

O know-how a ser repassado pelos franqueadores pode englobar, usualmente, ferramentas de gestão, processos de produção, metodologias de controle e práticas de vendas e/ou serviços, além da operação do negócio em si (LAFONTAINE, 1992).

O know-how da franqueadora é composto do conjunto de conhecimentos tácitos e explícitos, sendo possível classificá-lo como o terceiro tipo de conhecimento proposto por Nonaka et al (2013): a phronesis. A partir disso, propõe-se a seguinte classificação do conhecimento nas relações de franquia:

Quadro 1 - Tipos de conhecimento em franquias

\begin{tabular}{|c|c|}
\hline \multicolumn{2}{|c|}{ Tipos de conhecimento em franquias } \\
\hline Conhecimento explícito & Conhecimento tácito \\
\hline $\begin{array}{c}\text { Contratos de franquia } \\
\text { Manuais de franquia }\end{array}$ & Supervisão de campo \\
Treinamentos \\
$\begin{array}{c}\text { Circulares, normativas ou quaisquer outras fontes } \\
\text { escritas fornecidas aos franqueados ao longo da } \\
\text { relação }\end{array}$ & Convenção de Franqueados \\
& Reuniões \\
& Suporte contínuo \\
& Cultura organizacional \\
\hline \multicolumn{2}{|c|}{ Phronesis $=$ Know-how } \\
\hline
\end{tabular}

Fonte: elaborado pelos autores.

Ocorre que, do ponto de vista jurídico, a delimitação dos conhecimentos que integram know-how e a sua conceituação não são tão claras, o que representa um desafio para sua proteção jurídica. O conceito de know-how muitas vezes é relacionado aos elementos de 
engeneering, management e marketing referidos por Comparato (1975, p. 53-54) como os serviços de organização e métodos de venda do franqueador que diferenciam o contrato de franquia dos demais contratos do mesmo gênero (LAMY, 2002).

A Nova Lei de Franquias manteve a lógica legislativa da lei anterior, mantendo como obrigação principal do franqueador a entrega da COF, mas não dedicando-se a definir direitos e obrigações das partes da relação de franquia. Sobre a questão da proteção do conhecimento especificamente, vale destacar que a Nova Lei de Franquias apresentou uma modificação no inciso XIV, alínea 'a', do artigo $3^{\mathrm{o}^{3}}$ da antiga lei de franquias, tornando mais abrangente a descrição daqueles elementos que compõem o know-how dos franqueadores, na nova redação conferida pelo inciso VI, alínea 'a', do artigo $2^{{ }^{4}}$ da Nova Lei de Franquias. A nova lei traz luz ao conceito de know-how ao relacioná-lo com termos como "tecnologia de produto", "tecnologia de processos", "tecnologia de gestão", "informações confidenciais”, "segredos de indústria, de comércio, de finanças e de negócios”, mas, apesar desse avanço, ainda não traz previsões específicas relativas à proteção desse know-how.

Ainda, deve-se considerar que, no franchising, apesar do elemento central da relação residir na transferência vertical de know-how do franqueador para os seus franqueados, a observação empírica demonstra que a transmissão do conhecimento do franqueador, especialmente do conhecimento tácito, não ocorre simplesmente pela entrega dos manuais de franquia, pelo contrário, ela requer competências específicas e um longo processo de socialização entre franqueador e franqueados, privilegiando o contato face-a-face (HUSSLER e RONDE, 2017, p. 442); o desenvolvimento de produtos e serviços padronizados também pode auxiliar esse processo (WATSON et al, 2016).

Outro desafio empírico do franchising reside no fato de que há fluxos de transferência horizontal de conhecimento entre os franqueados, muitas vezes fazendo surgir novos conhecimentos ou, ainda, deformando o conhecimento original transferido pelo

\footnotetext{
${ }^{3}$ Art. $3^{\circ}$ Sempre que o franqueador tiver interesse na implantação de sistema de franquia empresarial, deverá fornecer ao interessado em tornar-se franqueado uma circular de oferta de franquia, por escrito e em linguagem clara e acessível, contendo obrigatoriamente as seguintes informações: (...)

XIV - situação do franqueado, após a expiração do contrato de franquia, em relação a:

a) know how ou segredo de indústria a que venha a ter acesso em função da franquia;

${ }^{4}$ Art. $2^{\circ}$ Para a implantação da franquia, o franqueador deverá fornecer ao interessado Circular de Oferta de Franquia, escrita em língua portuguesa, de forma objetiva e acessível, contendo obrigatoriamente: (...)

$\mathrm{XV}$ - situação do franqueado, após a expiração do contrato de franquia, em relação a:

a) know-how da tecnologia de produto, de processo ou de gestão, informações confidenciais e segredos de indústria, comércio, finanças e negócios a que venha a ter acesso em função da franquia;
} 
franqueador, o que ocorre mesmo quando há cláusulas contratuais tentando impedir esse fluxo (HUSSLER e RONDE, 2017, p. 442; PASWAN e WITTMANN, 2009, p. 173).

Por isso, Iddy e Alon (2019, p. 768) reforçam a relevância da gestão do conhecimento em franquias, defendendo que a vantagem competitiva de uma rede não vem da mera propriedade sobre o conhecimento, mas da habilidade de criar, transferir, receber e aplicar conhecimento. Gestão do conhecimento, em franquias, pode ser medido por três dimensões: criação, transferência e integração/aplicação (IDDY E ALON, 2019, p. 768), sendo este último o elemento mais desafiador (GRANT, 1996). Por isso, nem todos os fluxos de troca de conhecimento são desejados ou incentivados pelos franqueadores e, em algumas hipóteses, podem, inclusive, constituir infração ao contrato de franquia (HUSSLER e RONDE, 2017, p. 442; PASWAN e WITTMANN, 2009, p. 173).

\section{METODOLOGIA}

A pesquisa conduzida foi qualitativa e adotou como método de abordagem o estudo de caso. A opção por este método de abordagem é adequada por se tratar de uma questão de pesquisa do tipo "como" (YIN, 2014).

Para o estudo, foram selecionadas 3 (três) empresas franqueadoras com atuação majoritária no Brasil. A quantidade de casos foi selecionada conforme proposto por Eisenhardt (1989) a fim de que haja subsídios empíricos suficientes para apoiar a construção de uma teoria. A seleção das empresas levou em consideração 2 (dois) critérios primordiais, quais sejam: (a) a atividade desenvolvida pelo negócio franqueado, (b) o tamanho da rede de franquias, considerando a quantidade de unidades franqueadas.

O Caso 1 é de uma franqueadora de escolas que opera e expande sua rede por meio do franchising desde 2008. Atualmente, possui 63 unidades, sendo a grande maioria franqueadas. Sua atuação está limitada ao Brasil e sua visão de futuro é manter uma expansão orgânica. A pessoa que concedeu a entrevista em nome da franqueadora é sua sócia-fundadora e presidente. O Caso 2 é também de uma franqueadora de escolas, de outra categoria, que opera e expande sua rede por meio do franchising desde 2007. Atualmente, possui 300 unidades. Sua atuação abrange 16 países e sua visão de futuro é expandir na América Latina, especialmente no México, Colômbia, Peru e Argentina, mantendo a cobertura territorial no Brasil. A pessoa que concedeu a entrevista em nome da franqueadora é seu diretor jurídico. $\mathrm{O}$ Caso 3 é de uma franqueadora de clínicas de saúde que opera e expande sua rede por meio do 
franchising desde 2013. Atualmente, possui 48 unidades, sendo todas franqueadas. Sua atuação está limitada ao Brasil e sua visão de futuro é alcançar 100 unidades franqueadas e, a partir disso, expandir os negócios para outros ramos. A pessoa que concedeu a entrevista em nome da franqueadora é seu sócio-fundador e presidente.

$\mathrm{O}$ acesso às empresas franqueadoras se deu a partir de contatos estabelecidos junto às associações de classe e redes de franquias para identificação daquelas que guardaram ou manifestaram interesse em participar da pesquisa. Após a identificação e o contato preliminar, foram enviadas cartas-convite formais.

O estudo de caso foi conduzido somente junto a empresas franqueadoras, e não junto a franqueados vinculados a estas, em razão (i) de ser a empresa franqueadora a detentora do conhecimento originário da rede de franquias, (ii) de ser a empresa franqueadora a gestora da rede, e (iii) de ser a principal interessada na preservação do know-how.

Os dados foram obtidos por meio da realização de entrevistas e da coleta de arquivos (EISENHARDT, 1989). Os dados primários foram coletados em entrevistas realizadas com os gestores das empresas participantes do estudo. Foi adotado um roteiro semiestruturado, elaborado a partir das categorias de análise do referencial teórico expostas no Quadro 2 abaixo.

As entrevistas foram realizadas no período de novembro a dezembro de 2019, presencialmente ou através de ferramenta de videoconferência, e tiveram duração média de 1 a 2 horas. As entrevistas foram gravadas e posteriormente transcritas através do software Sonix.

Os dados secundários foram acessados mediante solicitação a cada uma das empresas participantes do estudo e consistiram em: Circular de Oferta de Franquia, Pré-Contrato de Franquia padrão, e Contrato de Franquia Empresarial padrão.

Após a coleta dos dados, foram conduzidas análises intracasos e intercasos com base na metodologia de análise de conteúdo proposta por Laurence Bardin (1977), tendo passado pelas etapas de pré-análise, exploração do material e tratamento dos resultados.

Finalmente, os resultados da análise dos dados foram comparados com a literatura de referência e complementar, com o objetivo de elevar o nível teórico das relações estabelecidas, refinar a construção das definições finais e fundamentar os novos discernimentos obtidos. 
Quadro 2 - Categorias de análise

\begin{tabular}{|c|c|}
\hline Categoria de análise & Referencial teórico \\
\hline Questões introdutórias & Não se aplica \\
\hline $\begin{array}{l}\text { 1. Definições de conhecimento } \\
\text { 1.1. Conceito de know-how } \\
\text { 1.2. Identificação de conhecimento explícito (codificado) } \\
\text { 1.3. Identificação de conhecimento tácito }\end{array}$ & $\begin{array}{l}\text { COMPARATO (1975); KOGUT (1992); NONAKA } \\
\text { (1994); NONAKA e TAKEUCHI (1995); GRANT } \\
\text { (1996); FEKETE (2003); NONAKA ET AL (2013); } \\
\text { GUETTA ET AL. (2013); GOROVAIA (2017); } \\
\text { LAFONTAINE (1992) }\end{array}$ \\
\hline $\begin{array}{l}\text { 2. Fluxos de criação, co-criação e transferência de } \\
\text { conhecimento } \\
2.1 \text {. Ferramentas para transferência } \\
2.2 \text {. Dificuldades no processo de transferência de } \\
\text { conhecimento } \\
2.3 \text {. Conhecimentos mais difíceis de transferir } \\
2.4 \text {. Co-criação de conhecimento com e entre } \\
\text { franqueados }\end{array}$ & $\begin{array}{l}\text { GRANT (1996); PASWAN e WITTMANN (2009); } \\
\text { BROOKES e ALTINAY (2016); HUSSLER e } \\
\text { RONDE (2017); GOROVAIA (2017); IDDY e } \\
\text { ALON (2019); FU-SHENG TSAI et al (2017); } \\
\text { WATSON et al (2016); GOROVAIA e } \\
\text { WINDSPERGER (2011) }\end{array}$ \\
\hline $\begin{array}{l}\text { 3. Proteção legal e contratual do conhecimento } \\
\text { 3.1. Proteção do know-how } \\
\text { 3.2. } \quad \text { Conflitos vivenciados }\end{array}$ & $\begin{array}{l}\text { NERY JR. (2010); BARBOSA (2009); ARAÚJO } \\
\text { (2015); ROQUE (2012); BEZERRA JR., (2014); } \\
\text { COELHO (2009); FEKETE (2003); RICHTER, } \\
\text { (2015); SANTOS (2016) }\end{array}$ \\
\hline
\end{tabular}

Fonte: Elaborado pelos autores.

\section{RESULTADOS DA PESQUISA REALIZADA}

\subsection{Análise intracasos}

\subsubsection{Caso 1 - Franqueadora de escolas (idiomas)}

Quanto à categoria '1. Definições de Conhecimento', a definição de know-how apresentada demonstra que se compreende (i) o aspecto prático, de saber-fazer alguma coisa, do know-how (KOGUT, 1992), bem como (ii) o aspecto de relação com o negócio em si, e não com um conhecimento genérico e geral (LAFONTAINE, 1992; FEKETE, 2003). As evidências indicam, ainda, que é possível identificar conhecimento explícito e tácito na franqueadora. Quanto ao conhecimento explícito, está codificado e é transmitido através dos manuais de franquia em formato físico e diversas outras instruções e orientações escritas disponibilizadas em intranet; quanto aos conhecimentos tácitos, são transmitidos através de treinamentos (GUETTA ET AL., 2013; GOROVAIA, 2017).

Quanto à categoria '2. Fluxos de criação, co-criação e transferência de conhecimento', as ferramentas de transmissão de conhecimento apresentadas estão em linha com as ferramentas sugeridas na literatura, quais sejam, manuais, treinamentos e supervisão de campo, além de contato direto e convenções de franqueados (GUETTA ET AL., 2013; GOROVAIA, 2017). Sobre as dificuldades vivenciadas na transmissão de conhecimento, se 
evidencia a dificuldade de os franqueados lerem os materiais, o que sugere que interações pessoais (treinamentos) podem gerar maior engajamento e, por consequência, uma transmissão de conhecimento mais eficaz (HUSSLER e RONDE, 2017, p. 442). Já sobre os conhecimentos mais difíceis de serem transmitidos ou absorvidos pelos franqueados, se evidencia que são aqueles relacionados a aspectos burocráticos e administrativos, bem como questões comerciais. Esse achado diverge parcialmente do que sugere a literatura. Segundo a literatura (BATTISTELLA et al, 2016; NONAKA e TAKEUCHI, 1995), o conhecimento tácito seria mais difícil de transmitir do que o conhecimento explícito. Todavia, na franqueadora em questão, conhecimentos explícitos (como as questões burocráticas e administrativas) apresentam dificuldade de absorção pelos franqueados. Sobre a ocorrência de co-criação e troca de conhecimento entre os franqueados, ou entre os franqueados e o franqueador, a entrevistada afirma que ocorrem trocas positivas, inclusive citando exemplos bem-sucedidos, o que corrobora o referencial teórico abordado no trabalho (LINDBLOM e TIKKANEN, 2010; FU-SHENG TSAI et al, 2017; NONAKA, 1994; HUSSLER e RONDE, 2017; PASWAN e WITTMANN, 2009).

Quanto à última categoria de análise '3. Proteção legal e contratual do conhecimento', as evidências sugerem que há falhas no sistema legal/contratual de proteção do know-how (ARAÚJO, 2015; BARBOSA, 2009). Para fins de complementar esta última categoria de análise, analisou-se a COF desta franqueadora para buscar as cláusulas contratuais que usualmente visam proteger o know-how, tendo sido identificada a previsão de cláusulas (i) definição do know-how, (ii) confidencialidade, (iii) não-competição e (iv) obrigações referentes ao encerramento da relação de franquia relativas à não utilização do know-how, conforme preconiza a literatura sobre o tema (FEKETE, 2003; RICHTER, 2015; SANTOS, 2016; COELHO, 2009). Por fim, a franqueadora em questão vivenciou somente uma situação de conflito com franqueado que envolveu a proteção do know-how e descumprimento de obrigações de confidencialidade e não-competição. Este achado diverge das conclusões inicialmente extraídas a partir do referencial teórico (JENSEN e MECKLING, 1976; RICHTER, 2015; VAROTTO e SILVA, 2017).

\subsubsection{Caso 2 - Franqueadora de escolas (outras categorias)}

Quanto à categoria '1. Definições de Conhecimento', a definição de know-how apresentada demonstra que se compreende a caraterística do know-how de relação com o 
negócio em si, e não com um conhecimento genérico ou teórico (LAFONTAINE, 1992; FEKETE, 2003); quanto ao aspecto prático, e não teórico (KOGUT, 1992), não há evidência específica, mas é possível sugerir que também se compreende. As evidências indicam, ainda, que é possível identificar conhecimento explícito e tácito na franqueadora. Quanto ao conhecimento explícito, está codificado e é transmitido, principalmente, através dos manuais de franquia e dos treinamentos (GUETTA ET AL., 2013; GOROVAIA, 2017; HUSSLER e RONDE, 2017); quanto aos conhecimentos tácitos, foram obtidas evidências práticas relativas ao fluxo de construção e aprimoramento de conhecimento em redes de franquia descrito na literatura de referência (PASWAN E WITTMANN, 2009; FU-SHENG TSAI et al, 2017).

Quanto à categoria '2. Fluxos de criação, co-criação e transferência de conhecimento', as ferramentas de transmissão de conhecimento apresentadas estão em linha com as ferramentas sugeridas na literatura, quais sejam, cerca de 20 manuais de franquia, entregues em formato digital, treinamento inicial, treinamentos pontuais, supervisão de campo e acompanhamento constante, webinars e gravações (GUETTA ET AL., 2013; GOROVAIA, 2017). Sobre as dificuldades vivenciadas na transmissão de conhecimento, as evidências sugerem que a empresa não vivencia, pois já possui o "know-how sobre como transmitir o know-how", e atribui a ausência de dificuldades ao grande foco da franqueadora em promover treinamentos. Já sobre os conhecimentos mais difíceis de serem transmitidos ou absorvidos pelos franqueados, as evidências sugerem que o perfil dos franqueados da franqueadora em questão tende a facilitar esse processo, por serem educadores, e refere que eventuais dificuldades de transmissão/absorção do conhecimento dependem do interesse e das aptidões individuais de cada franqueado. Além disso, as evidências indicam a dificuldade de fazer com que as pessoas leiam materiais mais extensos. Esse achado diverge parcialmente do que sugere a literatura, segundo a qual o conhecimento tácito seria mais difícil de transmitir do que o conhecimento explícito (BATTISTELLA et al, 2016; NONAKA e TAKEUCHI, 1995). Sobre a ocorrência de co-criação e troca de conhecimento entre os franqueados, ou entre os franqueados e o franqueador, as evidências são no sentido de que, em regra, não há; o que ocorre são feedbacks ou sugestões pontuais de melhorias em relação às metodologias, ferramentas ou processos, desenvolvidos pela franqueadora e que, a partir disso, a franqueadora, algumas vezes, escolhe fazer ajustes nas metodologias, ferramentas e processos desenvolvidos. As evidências demonstram também a existência de um Programa de Excelência criado que busca incentivar o compartilhamento de melhores práticas entre os 
franqueados. Esse achado vai parcialmente de encontro ao referencial teórico abordado no trabalho, que afirma a existência de transferência de conhecimento entre franqueados (LINDBLOM e TIKKANEN, 2010; FU-SHENG TSAI et al, 2017; NONAKA, 1994; HUSSLER e RONDE, 2017; PASWAN e WITTMANN, 2009).

Quanto à última categoria de análise '3. Proteção legal e contratual do conhecimento', as evidências indicam que a proteção se dá de três formas: (i) em esfera contratual, com cláusulas de confidencialidade e não-competição, (ii) através de uma constante evolução e codificação das novas práticas de negócio e, também (iii) através da utilização de pré-contrato, antes da celebração do contrato definitivo de franquia, pois, nesse formato, o franqueado só virá a ter acesso à grande parte do know-how da franqueadora após cumpridas todas as etapas preliminares necessárias para abertura de uma franquia, tais como, constituição de pessoa jurídica, locação do imóvel, obtenção de autorizações públicas, entre outras. Essas evidências relacionadas à proteção do know-how, englobando elementos jurídicos e negociais como protetores do know-how da franqueadora, são um achado que não estava contemplado no referencial teórico abordado. Para fins de complementar esta última categoria de análise, analisou-se a COF desta franqueadora para buscar as cláusulas contratuais que usualmente visam proteger o know-how, tendo sido identificada a previsão de cláusulas de (i) definição bastante genérica do que são informações confidenciais, mas não do know-how, (ii) confidencialidade, (iii) não-competição e (iv) obrigações referentes ao encerramento da relação de franquia relativas à não utilização do know-how, conforme preconiza a literatura sobre o tema (FEKETE, 2003; RICHTER, 2015; SANTOS, 2016; COELHO, 2009). Por fim, a franqueadora em questão nunca vivenciou conflitos com franqueados envolvendo o descumprimento de obrigações de confidencialidade e nãocompetição. Este achado diverge das conclusões inicialmente extraídas a partir do referencial teórico (JENSEN e MECKLING, 1976; RICHTER, 2015; VAROTTO e SILVA, 2017).

\subsubsection{Caso 3 - Franqueadora de clínicas de saúde}

Quanto à categoria '1. Definições de Conhecimento', a definição de know-how apresentada demonstra que se compreende (i) o aspecto prático, e não teórico, do know-how (KOGUT, 1992), bem como (ii) o aspecto de relação com o negócio em si, e não com um conhecimento genérico ou teórico (LAFONTAINE, 1992; FEKETE, 2003). As evidências sugerem que é possível identificar conhecimento explícito e tácito na franqueadora. Quanto ao 
conhecimento explícito, está codificado e é transmitido através dos manuais de franquia e de diversos outros materiais escritos e gravados em áudio e vídeo disponibilizados em plataforma EAD; quanto aos conhecimentos tácitos, são transmitidos através de treinamentos e acompanhamento no dia-a-dia (GUETTA ET AL., 2013; GOROVAIA, 2017).

Quanto à categoria '2. Fluxos de criação, co-criação e transferência de conhecimento', as ferramentas de transmissão de conhecimento apresentadas estão em linha com as ferramentas sugeridas na literatura, quais sejam, manuais, materiais codificados diversos (plataforma EAD), treinamentos e supervisão de campo, além de contato direto e reuniões com os franqueados (GUETTA ET AL., 2013; GOROVAIA, 2017). Sobre as dificuldades vivenciadas na transmissão de conhecimento, as evidências indicam que os franqueados, após absorverem os conhecimentos iniciais, se desengajam do processo de aprendizado e treinamento contínuo, além disso, refere que os franqueados deixam de reconhecer valor agregado na entrega de conhecimento feita pela franqueadora. Esse achado sugere conflitos de agência entre os interesses do principal (franqueador) e dos agentes (franqueados), conforme retratado pela literatura (JENSEN e MECKLING, 1976; ARAÚJO, 2007; VAROTTO e SILVA, 2017; JANG E PARK, 2019). Já sobre os conhecimentos mais difíceis de serem transmitidos ou absorvidos pelos franqueados, o entrevistado entende que não há especificamente, que a dificuldade/facilidade de transmissão depende do interesse e das aptidões individuais de cada franqueado. Esse achado diverge parcialmente do que sugere a literatura, segundo a qual o conhecimento tácito seria mais difícil de transmitir do que o conhecimento explícito (BATTISTELLA et al, 2016; NONAKA e TAKEUCHI, 1995). Sobre a ocorrência de co-criação e troca de conhecimento entre os franqueados, ou entre os franqueados e o franqueador, as evidências indicam que, em regra, não há; há apenas trocas pontuais entre franqueados. Esse achado vai parcialmente de encontro ao referencial teórico abordado no trabalho, que afirma a existência de transferência de conhecimento entre franqueados (LINDBLOM e TIKKANEN, 2010; FU-SHENG TSAI et al, 2017; NONAKA, 1994; HUSSLER e RONDE, 2017; PASWAN e WITTMANN, 2009). As evidências sugerem, ainda, que os franqueados compartilham mais informações relativas a acontecimentos negativos na rede de franquias do que buscam trocar informações com o objetivo de construção de conhecimento. Esses achados novamente sugerem a existência de conflitos de agência. 
Quanto à última categoria de análise '3. Proteção legal e contratual do conhecimento', as evidências indicam que a proteção se dá em esfera contratual e, também, em uma esfera negocial, pois o franqueado não compreende suficientemente o negócio franqueado a ponto de conseguir reproduzi-lo de forma independente e bem-sucedida. Para fins de complementar esta última categoria de análise, analisou-se a COF desta franqueadora para buscar as cláusulas contratuais que usualmente visam proteger o know-how, tendo sido identificada a previsão de cláusulas de (i) definição do que são informações confidenciais, mas não do know-how, (ii) confidencialidade, (iii) não-competição e (iv) obrigações referentes ao encerramento da relação de franquia relativas à não utilização do know-how, conforme preconiza a literatura sobre o tema (FEKETE, 2003; RICHTER, 2015; SANTOS, 2016; COELHO, 2009). Por fim, a franqueadora em questão vivenciou alguns conflitos com franqueados que envolveram o descumprimento de obrigações de confidencialidade e nãocompetição, e afirma, ainda, que as franquias de serviço não estão tão bem protegidas quanto a essas questões. Este achado confirma as conclusões inicialmente extraídas a partir do referencial teórico (JENSEN e MECKLING, 1976; RICHTER, 2015; VAROTTO e SILVA, 2017), especialmente, no ponto em que sugere que, em franquias de serviço, o nível de transferência de conhecimento é maior e, por isso, pode deixar o franqueador mais desprotegido no tocante à preservação do seu know-how (GOROVAIA e WINDSPERGER, 2011).

\subsection{Análises Intercasos}

As evidências sugerem que as franqueadoras compreendem o que é o know-how e conseguem identificar de forma satisfatória a existência de conhecimentos explícitos e tácitos.

A primeira categoria permite observar que, independentemente do tamanho da rede de franquias ou da estrutura/experiência da franqueadora, as empresas franqueadoras compreendem os conceitos básicos relacionados à definição de conhecimento e know-how e identificam nas franqueadas conhecimentos explícitos e tácitos, conforme sugere a literatura (HUSSLER e RONDE, 2017, p. 429; GOROVAIA, 2017, p. 235; FU-SHENG et al., 2017).

Na segunda categoria de análise é observado que as franqueadoras com mais tempo de atuação em franchising e/ou com uma rede de franquias maior em número de unidades franqueadas eventualmente vivenciam a troca de conhecimentos entre franqueados e entre franqueados e franqueadora de forma mais positiva. No entanto, é possível extrair das três 
franqueadoras que estas não visualizam essa troca de conhecimentos como uma efetiva cocriação de know-how, mas sim como um mero aprimoramento do know-how de propriedade da franqueadora. Para os franqueadores entrevistados, parece estar claro que o desenvolvimento do know-how e a sua transmissão aos franqueados são atribuições do franqueador, e que a troca de experiências ou aprimoramento de melhores práticas com envolvimento dos franqueados não se caracteriza como uma co-criação. Indica como tema interessante para futuras pesquisas a questão da apropriabilidade da inovação (TEECE, 1986) pelos franqueadores em relação a criações ou inovações que eventualmente poderiam ser de titularidade dos franqueados.

A terceira categoria demonstra que os franqueadores se preocupam em proteger o seu know-how, reconhecendo que o sistema legal apresenta lacunas e, por isso, utilizando-se de ferramentas contratuais e extracontratuais para tal. Algumas evidências sugerem que os franqueadores evitam os conflitos relacionados ao know-how, estando dispostos a negociar situações excepcionais para encerramento amigável da relação de franquia, por entenderem que a permanência de uma situação conflituosa é prejudicial para a rede de franquias.

Por fim, vale destacar que todas as franqueadoras pesquisadas preveem cláusulas semelhantes de confidencialidade e não-competição em suas Circulares de Oferta de Franquia.

\section{CONSIDERAÇÕES FINAIS}

Como fruto do referencial teórico e dos estudos de caso conduzidos neste trabalho, é possível extrair implicações teóricas, gerenciais e jurídicas que podem contribuir para o desenvolvimento das relações de franquia no Brasil.

Do ponto de vista teórico foi possível identificar (i) a importância do conhecimento e especialmente do know-how como recurso primordial das empresas franqueadoras, (ii) a existência de conhecimentos explícitos e tácitos nas franqueadoras brasileiras e adoção das ferramentas propostas na literatura de referência para transmissão de tais conhecimentos aos franqueados, notadamente, os manuais de franquia, os treinamentos, as consultorias de campo e o suporte recorrente, (iii) a existência de conhecimentos mais difíceis de transmitir do que outros, em que pese, na prática, os conhecimentos cuja transmissão é mais difícil não são aqueles indicados pela teoria, (iv) a relevância da proteção jurídica do know-how, especialmente através de cláusulas contratuais, e a ocorrência de conflitos nas redes de 
franquia relacionados ao know-how e, também, conflitos de agência de modo geral, conforme indicado pelas teorias de base. Por outro lado, não foi validada pelos estudos de caso: (i) a ocorrência efetiva de co-criação de conhecimento entre franqueados e franqueadores ou criação de conhecimento apenas pelos franqueados, tendo os franqueadores afirmado que os franqueados somente auxiliam no aprimoramento do know-how, mas não realizam efetiva cocriação; não restou validada, ainda, a existência efetiva de outros fluxos de co-criação envolvendo outros franqueadores, ou franqueados de outras redes.

Do ponto de vista gerencial, o trabalho trouxe contribuições aos franqueadores ao apresentar as formas contratuais e extracontratuais que podem permitir a proteção do knowhow desenvolvido pelos franqueadores. Ao longo do referencial teórico e dos estudos de caso conduzidos, validou-se a importância do conhecimento e especialmente do know-how como recurso primordial das empresas franqueadoras e a necessidade da sua adequada proteção. Diante da lacuna legislativa identificada, foi observada a utilização de cláusulas contratuais voltadas à proteção do conhecimento, mais especificamente, (i) cláusulas de confidencialidade, que visam que os franqueados não reproduzam ou repassem os conhecimentos adquiridos a terceiros, e (ii) cláusulas de não-competição e não-concorrência, que visam que os franqueados não implantem atividades relacionadas às atividades da franquia e/ou da franqueadora com utilização de conhecimento obtido através da relação de franquia; as cláusulas de não-competição e não-concorrência devem obedecer limitações temporais, territoriais e funcionais para fins de validade perante os tribunais. Além disso, foram identificadas alternativas extracontratuais para proteção do know-how.

Do ponto de vista jurídico, o trabalho contribui para que os profissionais do Direito possam redigir cláusulas contratuais mais efetivas que visem à proteção do know-how. Conforme se pode extrair do trabalho realizado, os contratos de franquia devem, em primeiro lugar, trazer um conceito claro e abrangente sobre os conhecimentos que compõem o knowhow do franqueador, visto que a legislação não traz esse conceito. Nesse conceito contratual, devem ser endereçados conhecimentos específicos desenvolvidos pelo franqueador (não contemplados aqueles que podem ser obtidos por quaisquer meios e não são específicos da rede de franquias), que sejam relacionados a aspectos práticos do negócio, ou seja, ao "saberfazer" alguma coisa, contemplando aspectos gerenciais, operacionais, financeiros, de produto, de processos, entre outros; esse conceito contemplará segredos de negócio (de indústria, de comércio), mas não somente. Ademais, esse conceito deve esclarecer que comporão o know- 
how do franqueador, também, aqueles conhecimentos que forem aprimorados, desenvolvidos ou criados no curso da relação de franquia, ainda que com participação ou sugestão do franqueado. Uma boa delimitação acerca do que compõem o know-how do franqueador protege ambas as partes da relação, franqueador e franqueado, pois traz clareza para a relação.

Além da conceituação e delimitação do know-how, a proteção passa por contratos de franquia que prevejam cláusulas de confidencialidade e não-competição. Tais cláusulas devem se sujeitar à limitação temporal - sugere-se o limite de 5 (cinco) anos a contar do término do contrato, a depender do contexto do caso concreto. As cláusulas de nãocompetição deverão prever, ainda, limitações territoriais - usualmente o território para o qual foi concedida exclusividade de atuação da franquia, com exceção de franqueadores em fase de expansão intensa, para os quais se admite um território mais extenso de limitação - e limitações funcionais - ou seja, descrição clara de qual atividade está vedada ao franqueado, o que deverá limitar-se às atividades da franquia, com exceções àquelas atividades que constituem a profissão regulamentada do franqueado com domínio de know-how previamente adquirido (como é o caso de médicos ou dentistas em franquias da mesma atividade).

Do ponto de vista legislativo, entende-se que não há sentido na proposição de modificações ao texto legal, visto que a nova Lei de Franquias foi publicada recentemente e, por isso, não deverá sofrer ajustes nos próximos anos. Portanto, a proteção do know-how deverá seguir em formato contratual e extracontratual conforme proposto.

Por fim, como limitações do estudo, ressalta-se que não foram realizadas entrevistas com os franqueados das redes objeto dos estudos de caso. Por essa razão, como contribuições para futuras pesquisas, sugere-se a continuidade dos estudos de caso contemplando também entrevistas com franqueados a fim de verificar suas percepções relativas, especialmente, aos fluxos de transmissão e co-criação de conhecimento, bem como à proteção do know-how e conflitos adjacentes, se assemelham ou diferem das percepções dos franqueadores.

\section{REFERÊNCIAS BIBLIOGRÁFICAS}

ARAÚJO, Fernando. Teoria Económica do Contrato. Coimbra: Almedina, 2007.

ARAÚJO, Rubia Maria Ferrão de. Novas formas de concorrência desleal em face dos avanços tecnológicos. Revista de Direito Empresarial, São Paulo, v. 11, p. 407 - 415, Set/Out, 2015. 
BARBOSA, Denis Borges. A Propriedade Intelectual no Século XXI. Rio de Janeiro: Editora Lumen Juris, 2009.

BARDIN, Laurence. Análise de conteúdo. Lisboa: Edições 70 Ltda, 1977.

BATTISTELlA, Cinzia; DE TONI, Alberto F.; PILLON, Robert. Inter-organisational technology/knowledge transfer: a framework from critical literature review. Journal of Techonology Transfer, vol. 41, p.1195-1234, 2016.

BEZERRA JR., Luis Martius Holanda. O Contrato de Franquia e a Violação dos Deveres Anexos de Conduta: a Boa-Fé como Fronteira de Atuação das Partes (da Culpa in Contrahendo à Culpa Post Pactum Finitum). In: RIDB, 2014, ano 3, no9, p. 6465 6535. Disponível em <http://www.cidp.pt /publicacoes /revistas/ridb/2014 /09/2014_09_06465_06535.pdf>.Acesso em: 05/10/2016.

BRASIL. Câmara dos Deputados. Projeto de Lei no 4386/2012, Deputado Alberto Mourão. Texto na íntegra. Disponível em: <http://www.camara.gov.br/ proposicoesWeb/fichadetramitacao?idProposicao=554337> . Acesso em: 30/01/2018.

BRASIL. Senado Federal. Atividade Legislativa. PLC - Projeto de Lei da Câmara, no 219 de 2015. Disponível em: <http://www25.senado.leg.br/web/atividade/ materias//materia/124525>. Acesso em: 30/01/2018.

BROOKES, Maureen; ALTINAY, Levent. Knowledge Transfer and Isomorphism in Franchise Networks. International Journal of Hospitality Management, Vol. 62, pp. 3342, 2017.

COELHO, Fábio Ulhoa. Curso de Direito Comercial, volume 1: Direito de Empresa. São Paulo: Saraiva, 2009.

COHEN, Wesley; LEVINTHAL, Daniel. Absorptive capacity: A new perspective on learning and innovation. Administrative Science Quarterly. Vol. 5, N. 1, p. 128-152, 1990.

COMBS, James; MICHAEL, Steven; CASTROGIOVANNI, Gary. Franchising: A Review and Avenues to Greater Theoretical Diversity. Journal of Management, 30(6), 2004, p. 907-931.

COMPARATO, Fábio Konder. Franquia e concessão de venda no Brasil: da consagração ao repúdio?. Revista de Direito Mercantil, p. 18 - 53, 1975.

COULON, Fabiano Koff; CANTALI, Fernanda Borghetti. Franquia e arbitragem: breve estudo a partir de emblemática decisão do Superior Tribunal de Justiça. Scientia Iuris, Londrina, v. 23, n. 1, p. 101-124, mar.2019. 
DANT, Rajiv; GRÜNHAGEN, Marko; WINDSPERGER, Josef. Franchising Research Frontiers For The Twenty-First Century. Journal Of Retailing, V. 87, N. 3, Set 2011, p. 253-268.

EISENHARDT, Kathleen M. Building Theories from Case Study Research. The Academy of Management Review, Vol. 14, No. 4, pp. 532-550, 1989.

FEKETE, Elisabeth Kasznar. O regime jurídico do segredo de indústria e comércio no direito brasileiro. Rio de Janeiro: Forense, 2003.

FU-SHENG, Tsai; CHIN-CHIUNG, Kuo; CHI-FANG, Liu. Knowledge-based View in the Franchising Research Literature. Journal of Economic and Social Thought, Issue 1, vol. 4, p. 97-107, 2017.

GOMES, Orlando. Contratos. Rio de Janeiro: Forense, 2008.

GOROVAIA, Nina. Knowledge transfer in franchising. In: HOY, Frank; PERRIGOT, Rozenn; TERRY, Andrew (Ed.). Handbook of Reserach in Franchising. Cheltenham, UK, Northampton, MA, USA: Edward Elgar Publishing, p. 234 - 244, 2017.

GOROVAIA, Nina; WINDSPERGER, Josef. Determinants of the Knowledge Transfer Strategy in Franchising: Integrating Knowledge-based and Relational Governance Perspectives. The Service Industries Journal, Vol. 33 (11-12), pp. 1117-1134, 2011.

GOROVAIA, Nina; WINDSPERGER, Josef. The choice of contract duration in franchising networks: A transaction cost and resource-based view. Industrial Marketing Management, v. 75, p. 125-133, 2018.

GRANT, Robert M. Toward a knowledge- based theory of the firm. Strategic Management Journal, v. 17, p. 109-122, Winter Special Issue, 1996.

GUETTA, Alain et al. Franchising Aprenda com os Especialistas. Rio de Janeiro: ABF RIO, 2013.

HUSSLER, Caroline; RONDE, Patrick Ronde. To be or not to be franchised? A knowledgebased perspective. Knowledge Management Research \& Practice, p. 429-445, 2017.

IDDY, Judith Jacob; ALON, Ilan. Knowledge management in franchising: a research agenda. Journal of Knowledge Management, Vol. 23 Issue: 4, pp.763-785, 2019.

JANG, SooCheong Shawn; PARK, Kwangmin. A sustainable franchisor-franchisee relationship model: Toward the franchise win-win theory. International Journal of Hospitality Management, v. 76, p. 13-24, 2019. 
JENSEN, Michael. C.; MECKLING, William. H. Theory of the firm: managerial behavior, agency costs and ownership structure. Journal of Financial Economics, No. 3, p. 305360, 1976.

KOGUT, Bruce, Zander, Udo. 'Knowledge of the firm, combinative capabilities, and the replication of technology', Organization Science, Vol. 3, p. 383-397, 1992.

LAFONTAINE, Francine et al. Agency theory and franchising: some empirical results. RAND journal of Economics, v. 23, n. 2, p. 263-283, 1992.

LAMY, Marcelo. Franquia pública. São Paulo. Ed. Juarez de Oliveira, 2002.

LEITE, Roberto Cintra. Franchising na criação de novos negócios. 2. ed. rev. e ampl. São Paulo: Atlas, 1991

LINDBLOM, Arto; TIKKANEN, Henrikki. Knowledge creation and business format franchising. Management Decision, Vol. 48, n. 2, p.179-188, 2010.

MARTINS, Fran. Contratos e Obrigações Comerciais. Rio de Janeiro: Forense, 1998.

NERY JR., Nelson. Segredo do Negócio - Livre Iniciativa. Soluções Práticas. vol. 1. São Paulo: Revista dos Tribunais Online, 2010.

NONAKA, Ikujiro. A dynamic theory of organizational knowledge creation. Organization Science, Vol. 5, N. 1, p. 14-37, 1994.

NONAKA, Ikujiro, TAKEUCHI, Hirotaka. The Knowledge Creating Company: How Japanese Companies Create the Dynamics of Innovation. New York: Oxford University Press, 1995.

NONAKA, Ikujiro et al. Dynamic fractal organizations for promoting knowledge-based transformation - A new paradigma for organizational theory. European Management Journal, 2013.

PASWAN, Audhesh; WITTMANN, Michael. Knowledge Management and Franchise Systems. Industrial Marketing Management, Vol. 38 No. 2, pp. 173-180, 2009.

PERRIGOT, Rozenn, PÉNARD, Thierry. Determinants of E-Commerce Strategy in Franchising: A Resource-Based View, International Journal of Electronic Commerce, v. 17, n. 3, p. 109-130, 2013.

RICHTER, Marina Nascimbem Bechtejew. A Relação de Franquia no Mundo Empresarial e as Tendências da Jurisprudência Brasileira. São Paulo: Almedina, 2015.

ROQUE, Sebastião José. Do Contrato de Franquia Empresarial. São Paulo: Ícone, 2012. 
SANTOS, Alexandre David. Aplicabilidade e limites das cláusulas de não concorrência nos contratos de franquia. 2016. 117 f. Dissertação (Mestrado em Direito), Escola de Direito de São Paulo, da Fundação Getúlio Vargas, São Paulo, 2016. Disponível em: <http://bibliotecadigital.fgv.br/dspace/handle/10438/ 17511?show=full> Acesso em: 21/07/2018.

TEECE, David J. Profiting from technological innovation: Implications for integration, collaboration, licensing and public policy. In: The Transfer and License of Know-how and Intelectual Property Understanding the Multinacional Entrerprise in the Modern World. World Scientific Publishing Co.,1986.

VAROTTO, Luis Fernando; SILVA, Leonardo Aureliano. Evolution in franchising: Trends and new perspectives. Review of International Business. São Paulo, v.12, n. 3, p. 31-42, sep./dec. 2017.

WATSON, Anna et al. When do franchisors select entrepreneurial franchisees? An organizational identity perspective. Journal of Business Research, vol. 69, p. 59345945, 2016.

WELSH, Dianne et al. A Resource-Based View Of Three Forms Of Business In The

Startup Phase: Implications For Franchising. Journal of Small Business Strategy, vol. 22, n. 1., p. 47-65, 2011.

YIN, Robert K. Case Study Research: Design and Methods. Fifth Edition, SAGE Publications, Inc. Los Angeles, London, New Delhi, Singapore: 2014. 